\title{
Nonlinear Harmonics in the High-Gain Harmonic Generation (HGHG) Experiment
}

\author{
S.G. Biedron, H. P. Freund ${ }^{\dagger}$, S.V. Milton, L-.H. Yu ${ }^{\dagger \dagger}$, and X.J. Wang ${ }^{\dagger \dagger}$ \\ Advanced Photon Source, Argonne National Laboratory, Argonne, Illinois 60439 \\ ${ }^{\dagger}$ Science Applications International Corp., McLean, Virginia 22102 \\ ${ }^{\dagger+}$ Brookhaven National Laboratory, Upton, New York 11973
}

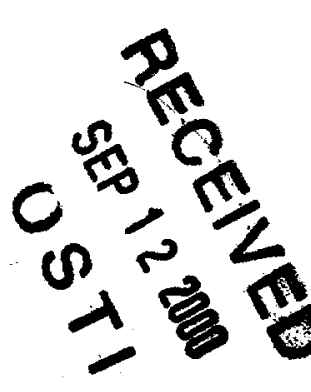

\section{Introduction}

A single-pass, high-gain free-electron laser (FEL) experiment based on the highgain harmonic generation (HGHG) theory is underway at the Accelerator Test Facility (ATF) at Brookhaven National Laboratory (BNL) in collaboration with the Advanced Photon Source (APS) at Argonne National Laboratory (ANL) [1]. This project achieved first lasing in August 1999, when gain of $10^{7}$ above spontaneous was measured [2,3]. It has been shown through both the 1D [4-7] and 3D [8] analytical models and in 3D simulations [5-7] that the higher nonlinear harmonics are expected to grow at rates that scale in inverse proportion to the harmonic number in all single-pass, high-gain FELs. Also, the powers in these harmonics are expected to be substantial. An HGHG FEL configuration already implements frequency up-conversion (as explained briefly in the next section), and, in such a system, these higher nonlinear harmonics are unusually interesting, as even shorter wavelengths can be exploited simultaneously. The specific case of the simulated higher nonlinear harmonic output for the BNL/APS HGHG experiment will be examined here.

\section{High-Gain Harmonic Generation (HGHG) Theory}

In a self-amplified spontaneous emission (SASE) FEL, the spontaneous emission "noise" serves to ignite the FEL bunching process, resulting in a noisy output. In a seeded 


\section{DISCLAIMER}

This report was prepared as an account of work sponsored by an agency of the United States Government. Neither the United States Government nor any agency thereof, nor any of their employees, make any warranty, express or implied, or assumes any legal liability or responsibility for the accuracy, completeness, or usefulness of any information, apparatus, product, or process disclosed, or represents that its use would not infringe privately owned rights. Reference herein to any specific commercial product, process, or service by trade name, trademark, manufacturer, or otherwise does not necessarily constitute or imply its endorsement, recommendation, or favoring by the United States Government or any agency thereof. The views and opinions of authors expressed herein do not necessarily state or reflect those of the United States Government or any agency thereof. 


\section{DISCLAIMER}

\section{Portions of this document may be illegible in electronic image products. Images are produced from the best available original document.}


(amplified) FEL, however, the output radiation quality is related to the coherence properties of the seed. In both cases, the process saturates and maximum power is reached. In practical design, this saturation point should be made to occur in the shortest possible distance. It is well known that in order to achieve this, both SASE and amplifier schemes require a high peak current, low emittance, and low energy-spread electron beam, as well as a properly shimmed undulator, to reduce magnetic error effects on the electron beam trajectory. From a machine user's standpoint, the amplifier scheme is more desirable due to the quality of the output radiation. To reach ultrashort wavelengths in this mode of operation, however, a seed laser already at the desired short wavelength is required. In the hard x-ray regime, for example, no seed is currently available.

Another possible mode of FEL operation capable of providing a very desirable output light beam is HGHG $[9,10]$. Here, a coherent radiation source, at a subharmonic of the desired output radiation wavelength overlaps an electron beam resonant with the seed radiation. Energy modulation of the electron beam with a period equal to the seed radiation is the result. Following this modulation, a dispersive section is traversed. Spatial bunching is induced with a strong higher harmonic content. The beam then enters a second undulator, the radiative section, tuned to resonance at the desired harmonic. (In the BNLAPS HGHG experiment, the second harmonic is of interest.) Coherent radiation and ultimately saturation at this higher harmonic is then achieved within a reasonable number of undulator periods and with an excellent beam quality, as compared to the SASE process. Recall that this better beam quality is defined by the coherent seed source. Although this method has been proven at $5.3 \mu \mathrm{m}$, it could quite possibly be extended to higher energies, where the radiator is tuned to a much higher harmonic, and possibly 
achieve saturation in the UV, VUV, or x-ray regimes. A schematic of the HGHG process for the specific design case of the BNLAPS collaborative experiment is provided in Figure 1.

\section{Nonlinear Harmonic Generation in Single-Pass, Free-Electron Lasers}

The nonlinear harmonics grow as bunching at the fundamental occurs. In a planar undulator, which will be considered here, the natural motion of the electron beam causes the odd harmonics to be most significant in the forward direction. It is important to observe that all the harmonic growth rates are faster than the fundamental growth rate; the gain length scales inversely with the harmonic number [4-8].

In order to illustrate this scaling, consider Maxwell's equation in 1-D

$$
\left(\frac{\partial^{2}}{\partial z^{2}}-\frac{1}{c^{2}} \frac{\partial^{2}}{\partial t^{2}}\right) E_{x}(z, t)=\frac{4 \pi}{c^{2}} \frac{\partial}{\partial t} J_{x}(z, t)
$$

where the electric field is given by

$$
E_{x}(z, t)=\frac{1}{2} \sum_{h} \hat{E}_{h}(z) \exp \left[i h k_{0}(z-c t)\right]+c . c .
$$

and the source current is given in terms of a nonlinear conductivity, $\sigma_{h}^{(N L)}$,

$$
J_{x}(z, t)=\frac{1}{2} \sum_{h}\left[\sigma_{h}^{(L)} \hat{E}_{h}+\sigma_{h}^{(N L)} \hat{E}_{1}^{h}\right] \exp \left[i h k_{0}(z-c t)\right]+c . c .
$$

where $\sigma_{h}^{(L)}$ describes the linear interaction. The detailed form for the nonlinear conductivity is not specified here, yet it is included implicitly in the nonlinear formulation. As stated above, these nonlinear terms are driven by bunching at the fundamental, and so we can write Maxwell's equations to lowest order as

$$
\frac{d}{d z} \hat{E}_{h} \equiv-\frac{2 \pi}{c}\left(\sigma_{h}^{(L)} \hat{E}_{h}+\sigma_{h}^{(N L)} \hat{E}_{1}^{h}\right)
$$


Therefore, if the fundamental grows as $\hat{E}_{1} \approx \exp [\Gamma z]$ then the harmonics will grow as $\hat{E}_{1}^{h} \approx \exp [h \Gamma z]$, and the gain length scales as $L_{g} \approx(2 h \Gamma)^{-1}$. The scaling of the gain length with the harmonic number is characteristic of the nonlinear mechanism. This is a well-known phenomenon in traveling wave tubes (TWTs) [11], has been seen in a 1D analysis for the first and third harmonics in an FEL [4-7], and was exemplified with a 3D simulation code [5-7]. More recently, a 3D analytical model has been developed and shows very good agreement with the previous work [8].

\section{Harmonic Output in the BNL/APS HGHG Case}

The output power of HGHG at the fundamental, with respect to the resonance condition of the radiative section of $5.3 \mu \mathrm{m}$, has been estimated $[1,12]$ and measurements have been made $[2,3]$. The theoretical calculations were performed using the electron beam, seed laser, and magnetic parameters listed in Figure 1.

The HGHG simulations including the higher, nonlinear harmonics, relative to the radiative section, were performed using the $3 D$, polychromatic, nonundulator averaged code, MEDUSA [13,14,5-7]. Again, the design parameters shown in Figure 1 were used. For a dispersive strength of $1.7 \mathrm{kG}\left(\mathrm{R}_{56}=0.97 \mathrm{~mm}\right)$, an input seed laser power of 0.7 MW $\left(E_{0}=1.62 \times 10^{7} \mathrm{~V} / \mathrm{m}\right)$, an incoherent electron beam energy spread of $0.043 \%$, a peak current of $110 \mathrm{~A}$, and a normalized emittance of $4 \pi \mathrm{mm}$-mrad, the powers as a function of distance along the HGHG line are shown in Figure 2 for the fundamental of the radiative section $(5.3 \mu \mathrm{m})$ and its four higher harmonics. Note the radiative section begins at $2.65 \mathrm{~m}$. The higher harmonics are the second through fifth harmonics to the radiative section resonant wavelength $(5.3 \mu \mathrm{m})$, but note they are the fourth, sixth, eighth, and 
tenth harmonics of the input seed laser $(10.6 \mu \mathrm{m})$. This multiplicative increase in the frequency up-conversion based on the ratio of the resonant wavelengths of the radiative and modulative sections in HGHG makes these nonlinear harmonics even more fruitful than those found in SASE and amplifier schemes. In other words, in HGHG the shorter wavelengths are attainable more readily and with more control than the other schemes.

Note the above-described case has slightly better performance than the nominal beam case for the fundamental as well as the harmonics and was found by lowering the dispersive section from $2.30 \mathrm{kG}$ to $1.7 \mathrm{kG}$ (reducing $\mathrm{R}_{56}$ from $1.67 \mathrm{~mm}$ to $0.97 \mathrm{~mm}$ ). In addition to the simulations at this case, parameter scans were performed by varying dispersion section strength, seed laser power density, emittance, energy spread, and peak current, about the nominal design case. Figures 3-7 show the output power and saturation length for each of these scans for the fundamental of the radiative section $(5.3 \mu \mathrm{m})$ and the four higher harmonics $(2.65,1.77,1.33$, and $1.06 \mu \mathrm{m})$.

Upon examination of the parameter scans of dispersive section strength and the input seed power, some comments can be made. Both of these parameters contribute to the efficiency of the HGHG process and the results of the scans resemble each other greatly. For example, reduced HGHG efficiency will result from too little energy modulation or, alternatively, too little phase-space rotation in the dispersive section leads to an underbunched electron beam at the entrance of the radiative section. Reduced HGHG efficiency will also result from too much energy modulation or too much phasespace rotation in the dispersive section as the beam is overbunched when entering the radiative section. Basically, there is a balance between saturated output power and saturation length based on the dispersive section strength and the degree of energy 
modulation. The optimum HGHG efficiency, if based solely on the degree of energy modulation and dispersive strengths, is the shortest distance to saturation in the radiative section. The equation governing this optimum is expressed as

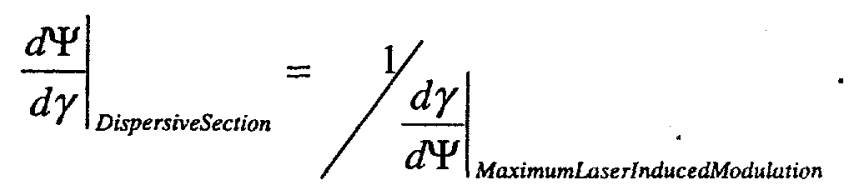

The saturated power decreases fairly readily with degraded electron beam energy spread, peak current, and emittance, and increases with beam quality. The saturation length also increases with electron beam degradation and is reduced as the beam quality sharpens.

\section{Conclusion}

The nonlinear harmonic output in all single-pass, high-gain FELs is important, as shorter wavelengths are achievable. The harmonic output from HGHG is particularly interesting, however, since even shorter wavelengths can be achieved in such a configuration, and they are imprinted for coherence unlike the noisy SASE case. (The same is true when using the Bonofacio et al. two-undulator scheme [15] as well.) In this presentation, the harmonic output from HGHG was shown in simulation by sensitivity studies of the fundamental and four higher harmonics of the radiative section of the BNL/APS HGHG experiment. Harmonic measurements are ongoing at this experiment and have proven to be comparable to theory/simulation [16].

This harmonic experiment will also be performed for the fundamental and second harmonic with wavelengths of 530 and $265 \mathrm{~nm}$, respectively, corresponding to an electron beam energy of $\approx 217 \mathrm{MeV}$ in a purely SASE mode of operation at the Advanced Photon Source's SASE FEL at Argonne National Laboratory [7,17]. 
It is the desire of the light source community to achieve shorter wavelengths, on the order of $1 \AA$, and various prototypical experiments other than HGHG are underway [18] using the fundamental radiation. To achieve even shorter wavelengths with lower electron beam energies, the nonlinear harmonics, which are generated in self-amplified spontaneous emission (SASE), amplifier, and HGHG FEL schemes, will be important. In addition, the use of soft $\mathrm{x}$-ray seed lasers [19] along with combinations of the above schemes will also be important in obtaining these shorter wavelengths [20-21].

\section{Acknowledgements}

Many thanks our extended to our HGHG collaboration friends Marcus Babzien, Adnan Doyuran, and Timur Shaftan for helping with the experimental measurements.

This work is supported by the U.S. Department of Energy, Office of Basic Energy Sciences, under Control No. W-31-109-ENG-38.

\section{References}

[1] L.-H. Yu, M. Babzien, I. Ben-Zvi, L.F. DiMauro, A. Doyuran, W. Graves, E. Johnson, S. Krinsky, R. Malone, I. Pogorelsky, J. Skaritka, G. Rakowsky, L. Solomon, X.J. Wang, M. Woodle, V. Yakimenko (BNL), S.G. Biedron, J.N. Galayda, V. Sajaev, I. Vasserman (ANL), "The Status of a High-Gain Harmonic Generation Experiment at the Accelerator Test Facility," Proceedings of the IEEE 1999 Particle Accelerator Conference, (1999) 2470.

[2] L.-H. Yu, M. Babzien, I. Ben-Zvi, L.F. DiMauro, A. Doyuran, W. Graves, E. Johnson, S. Krinsky, R. Malone, I. Pogorelsky, J. Skaritka, G. Rakowsky, L. Solomon, X.J. Wang, M. Woodle, V. Yakimenko (BNL), S.G. Biedron, J.N. Galayda, E. Gluskin, J. Jagger, V. Sajaev, I. Vasserman (ANL), "First Lasing of a High-Gain Harmonic Generation Free-Electron Laser Experiment," Nucl. Instrum. Meth. A445 (2000) 301. 
[3] L.-H. Yu, M. Babzien, I. Ben-Zvi, L.F. DiMauro, A. Doyuran, W. Graves, E. Johnson, S. Krinsky, R. Malone, I. Pogorelsky, J. Skaritka, G. Rakowsky, L. Solomon, X.J. Wang, M. Woodle, V. Yakimenko (BNL), S.G. Biedron, J.N. Galayda, E. Gluskin, J. Jagger, V. Sajaev, I. Vasserman (ANL), "High-Gain Harmonic Generation Free-Electron Laser," accepted to Science, in press.

[4] R. Bonifacio, L. DeSalvo, and P. Pierini, "Large Harmonic Bunching in a High-Gain Free-Electron Laser,” Nucl. Instrum. Meth. A293 (1990) 627.

[5] H.P. Freund, S.G. Biedron, S.V. Milton, "Nonlinear Harmonic Generation in FreeElectron Lasers," IEEE Journal of Quantum Electronics 36 (2000) 275.

[6] S.G. Biedron, H.P. Freund, and S.V. Milton, "3D FEL code for the simulation of a high-gain harmonic generation experiment," in Free-Electron Laser Challenges II, Harold E. Bennett, David H. Dowell, Editors, Proceedings of SPIE 3614 (1999) 96.

[7] H.P. Freund, S.G. Biedron, S.V. Milton, "Nonlinear Harmonic Generation and Proposed Experimental Verification in SASE FELs," Nucl. Instrum. Meth. A445 (2000) 53.

[8] Z. Huang and K. Kim, "Nonlinear Harmonic Generation of Coherent Amplification and Self-Amplified Spontaneous Emission," Proceedings of the $22^{\text {nd }}$ Annual FreeElectron Laser Conference, Durham, North Carolina, August 13-18, 2000.

[9] L.-H. Yu, "Generation of intense uv radiation by subharmonically seeded single-pass free-electron lasers," Phys. Rev. A44 (1991) 5178.

[10] I. Ben-Zvi et al., "Design of a harmonic generation free-electron laser experiment at Brookhaven National Laboratory," Nucl. Instrum. Meth. A318 (1992) 208. 
[11] J.W. Hansen, G.A. Lange, A.S. Rostad and R.L. Woods, "System aspects of communications TWTAs on how to deal with the tube manufacturer to your best advantage," Hughes Aircraft Company Electron Dynamics Division Applications Note, August 1992.

[12] HGHG Design Handbook, BNL Report (1996).

[13] H.P. Freund, "Nonlinear theory of short wavelength free-electron lasers," Phys. Rev. E52 (1995) 5401.

[14] S.G. Biedron, H.P. Freund, L.-H.Yu, "Parameter Analysis for a High-Gain Harmonic Generation FEL Using a Recently Developed 3D Polychromatic Code," Nucl. Instrum. Meth. A445 (2000) 95.

[15] R. Bonifacio, L. de Salvo Souza, P. Pierini, and E.T. Scharlemann, "Generation of XUV light by resonant frequency tripling in a two-wiggler free-electron laser amplifier," Nucl. Instrum. Meth. A296 (1990) 787.

[16] A. Doyuran, L.-H. Yu, M. Babzien, I. Ben-Zvi, L.F. DiMauro, W. Graves, E. Johnson, S. Krinsky, R. Malone, I. Pogorelsky, J. Skaritka, G. Rakowsky, T. Shaftan, L. Solomon, X.J. Wang, M. Woodle, V. Yakimenko (BNL), S.G. Biedron, J.N. Galayda, E. Gluskin, J. Jagger, V. Sajaev, I. Vasserman (ANL), "High Gain Harmonic Generation Experiment," Proceedings of the $22^{\text {nd }}$ Annual Free-Electron Laser Conference, Durham, North Carolina, August 13-18, 2000.

[17] S.V. Milton, E. Gluskin, S.G. Biedron, R.J. Dejus, P.K. Den Hartog, J.N. Galayda, K.-J. Kim, J.W. Lewellen, E.R. Moog, V. Sajaev, N.S. Sereno, G. Travish, N.A. Vinokurov et al., "Observation of Self-Amplified Spontaneous Emission and Exponential Growth at 530 nm," Phys. Rev. Lett. 85 (2000) 988. 
[18] S.V. Milton et al., "FEL Development at the APS: The APS SASE FEL," in FreeElectron Laser Challenges II, Harold E. Bennett, David H. Dowell, Editors, Proceedings of SPIE 3614 (1999) 86; The VISA Collaboration (BNL, LANL, LLNL, SLAC, UCLA), VISA Proposal, "Proposal for a SASE-Free-electron Laser Experiment, VISA, at the ATF Linac," April 1998; "A VUV Free Electron Laser at the TESLA Test Facility at DESY: Conceptual Design Report," DESY Print, TESLA-FEL 95-03, June 1995; LCLS Design Study Group, Linac Coherent Light Source (LCLS) Design Study Report, SLACR-521 (1998).

[19] S.G. Biedron, H.P. Freund, S.V. Milton, Y. Li, "Simulation of the fundamental and nonlinear harmonic output from an FEL amplifier with a soft x-ray seed laser," Proceedings of $7^{\text {th }}$ European Accelerator Conference (EPAC) 2000, 26-30 June, Vienna, to be published.

[20] S.G. Biedron, S.V. Milton, and H.P. Freund, "Modular Approach to Achieving the Next Generation Light Source," Proceedings of the $22^{\text {nd }}$ Annual Free-Electron Laser Conference, Durham, North Carolina, August 13-18, 2000.

[21] L.H. Yu and J. Wu, "Cascading Stages of High-Gain Harmonic Generation to Produce Coherent Hard X-rays," Proceedings of the $22^{\text {nd }}$ Annual Free-Electron Laser Conference, Durham, North Carolina, August 13-18, 2000. 


\section{List of Figures:}

Figure 1: The BNL/APS HGHG experimental layout.

Figure 2: Power (W) versus distance (m) along the HGHG line for the (a) $5.3 \mu \mathrm{m}$, (b) $2.65 \mu \mathrm{m}$, (c) $1.77 \mu \mathrm{m}$, (d) $1.33 \mu \mathrm{m}$, and (e) $1.06 \mu \mathrm{m}$ output radiation.

Figure 3: Saturation Length (m) and Saturated Power (W) versus dispersive section strength (kG) for the (a) $5.3 \mu \mathrm{m}$, (b) $2.65 \mu \mathrm{m}$, (c) $1.77 \mu \mathrm{m}$, (d) $1.33 \mu \mathrm{m}$, and (e) $1.06 \mu \mathrm{m}$ output radiation.

Figure 4: Saturation Length (m) and Saturated Power (W) versus input seed laser power (MW) for the (a) $5.3 \mu \mathrm{m}$, (b) $2.65 \mu \mathrm{m}$, (c) $1.77 \mu \mathrm{m}$, (d) $1.33 \mu \mathrm{m}$, and (e) $1.06 \mu \mathrm{m}$ output radiation.

Figure 5: Saturation Length (m) and Saturated Power (W) versus energy spread (\%) for the (a) $5.3 \mu \mathrm{m}$, (b) $2.65 \mu \mathrm{m}$, (c) $1.77 \mu \mathrm{m}$, (d) $1.33 \mu \mathrm{m}$, and (e) $1.06 \mu \mathrm{m}$ output radiation. Figure 6: Saturation Length (m) and Saturated Power (W) versus peak current (A) for the (a) $5.3 \mu \mathrm{m}$, (b) $2.65 \mu \mathrm{m}$, (c) $1.77 \mu \mathrm{m}$, (d) $1.33 \mu \mathrm{m}$, and (e) $1.06 \mu \mathrm{m}$ output radiation.

Figure 7: Saturation Length $(\mathrm{m})$ and Saturated Power $(\mathrm{W})$ versus emittance ( $\pi \mathrm{mm}-\mathrm{mrad})$ for the (a) $5.3 \mu \mathrm{m}$, (b) $2.65 \mu \mathrm{m}$, (c) $1.77 \mu \mathrm{m}$, (d) $1.33 \mu \mathrm{m}$, and (e) $1.06 \mu \mathrm{m}$ output radiation. 


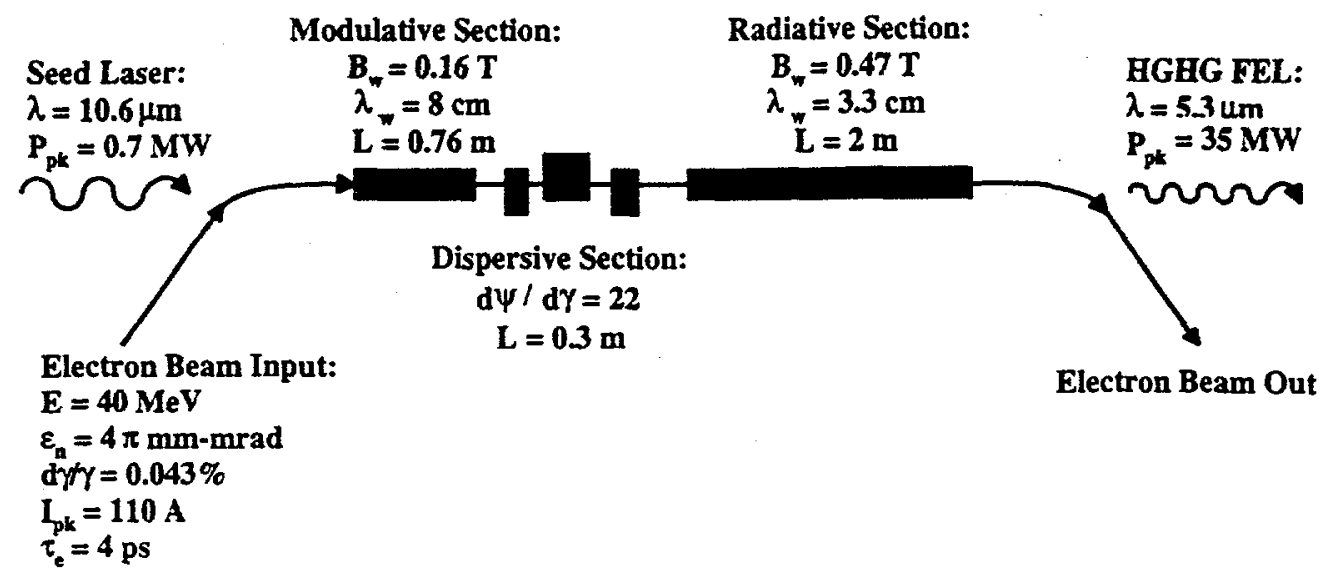

Figure 1: The BNL/APS HGHG experimental layout. 


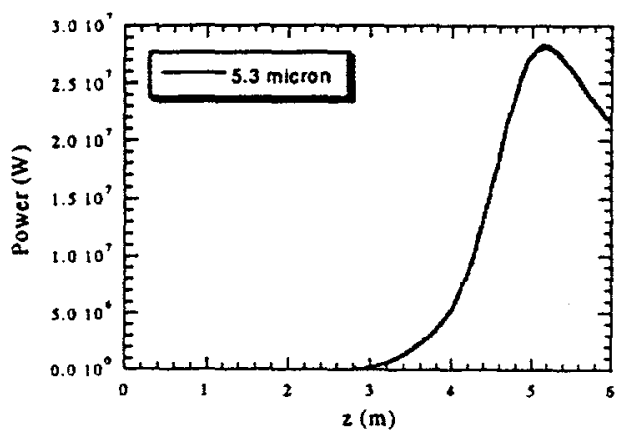

(a)

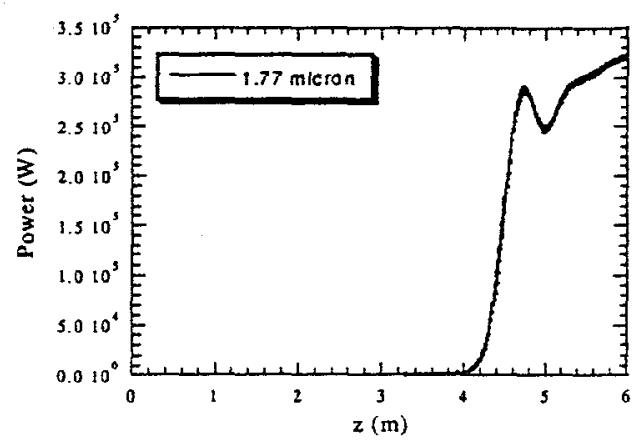

(c)

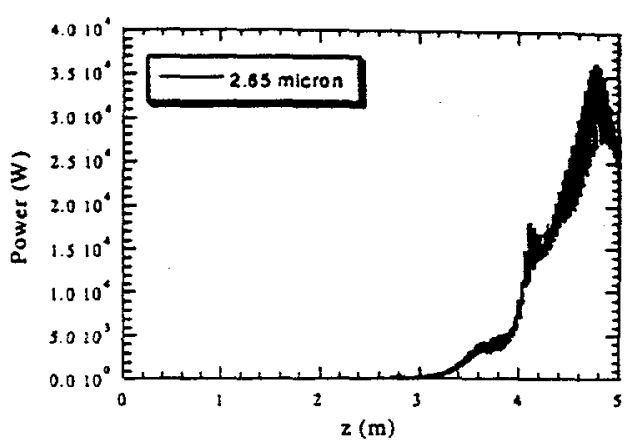

(b)

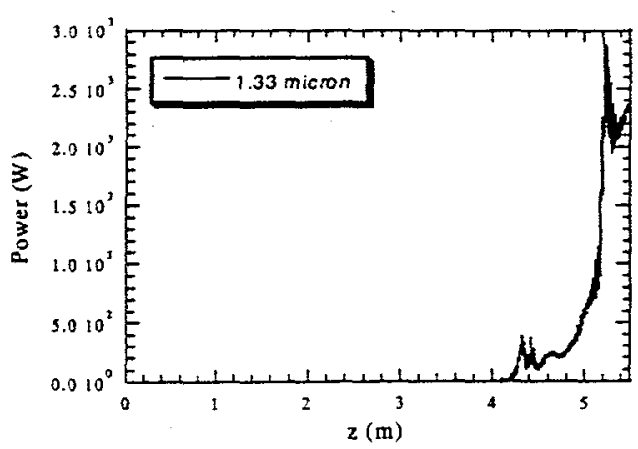

(d)

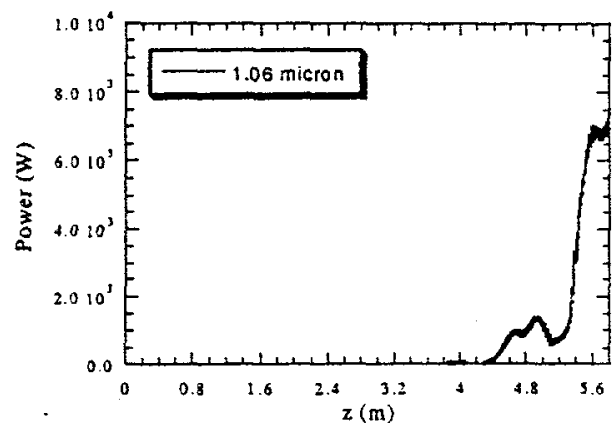

(e)

Figure 2: Power (W) versus distance (m) along the HGHG line for the (a) $5.3 \mu \mathrm{m}$,

(b) $2.65 \mu \mathrm{m}$, (c) $1.77 \mu \mathrm{m}$, (d) $1.33 \mu \mathrm{m}$, and (e) $1.06 \mu \mathrm{m}$ output radiation. 


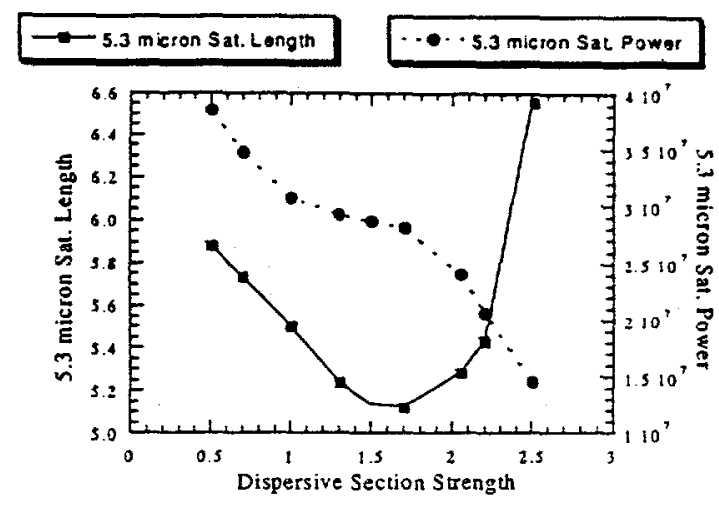

(a)

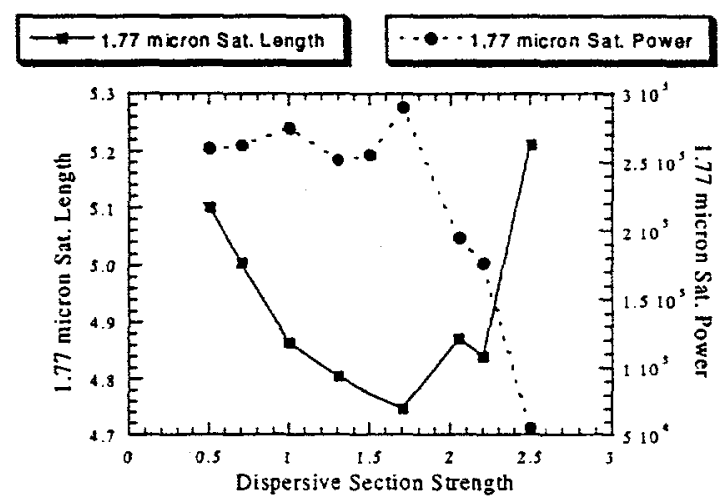

(c)

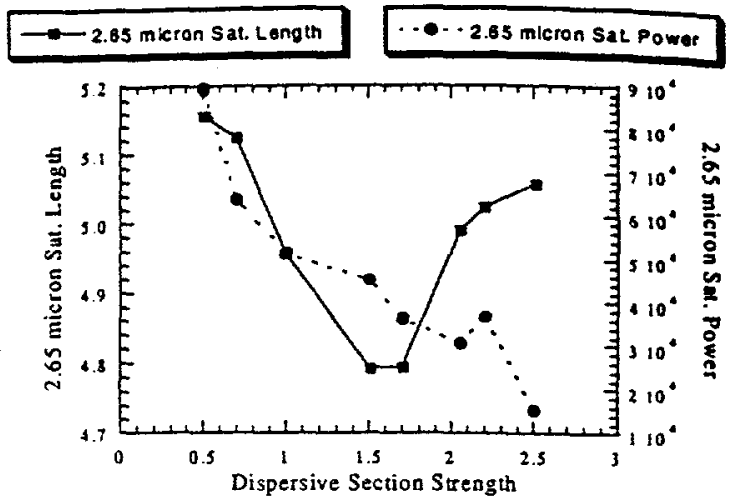

(b)

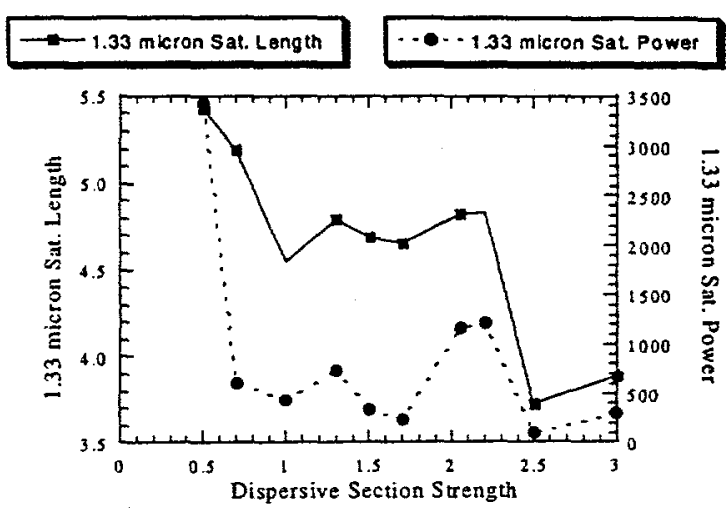

(d)

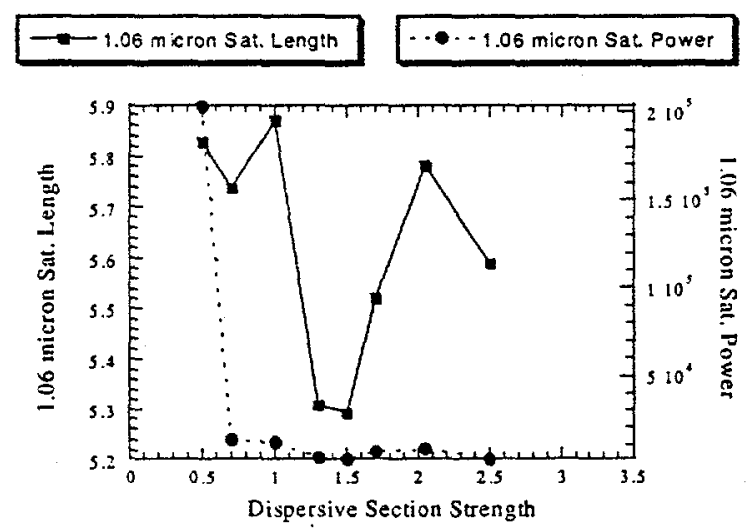

(e)

Figure 3: Saturation Length (m) and Saturated Power (W) versus dispersive section strength (kG) for the (a) $5.3 \mu \mathrm{m}$, (b) $2.65 \mu \mathrm{m}$, (c) $1.77 \mu \mathrm{m}$, (d) $1.33 \mu \mathrm{m}$, and (e) 1.06 $\mu \mathrm{m}$ output radiation. 


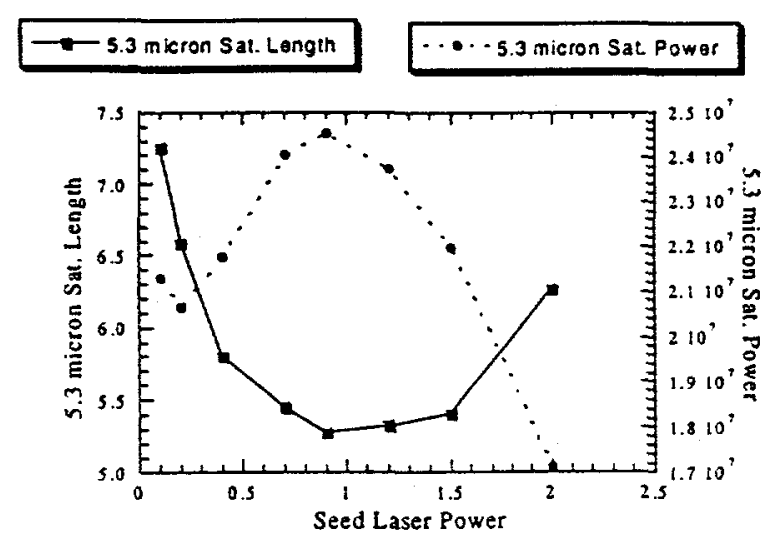

(a)

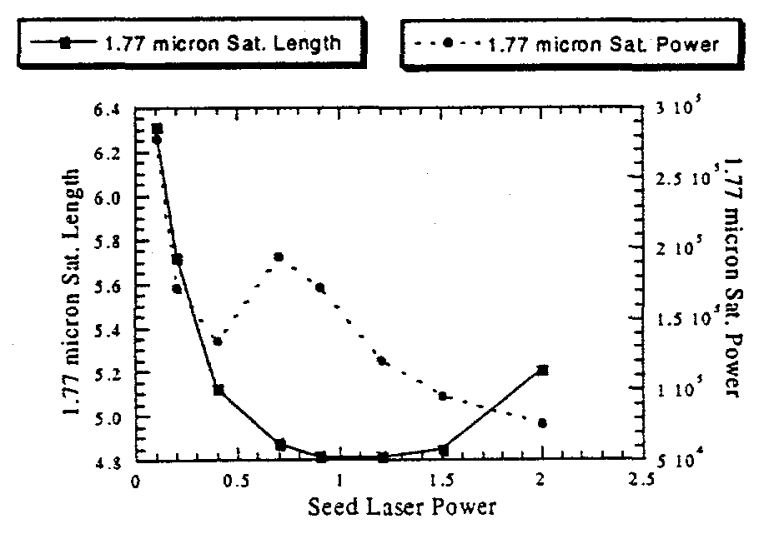

(c)

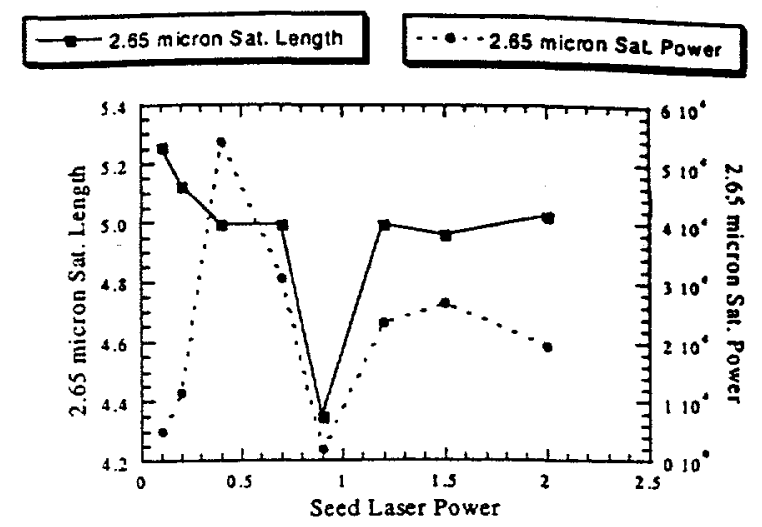

(b)

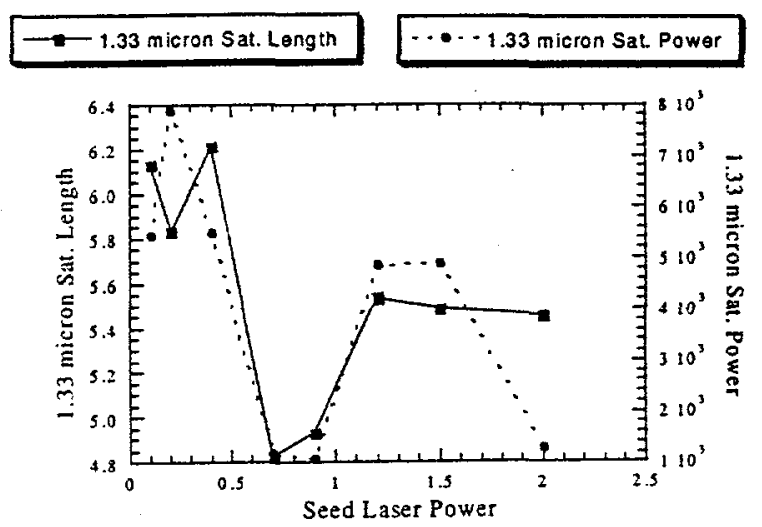

(d)

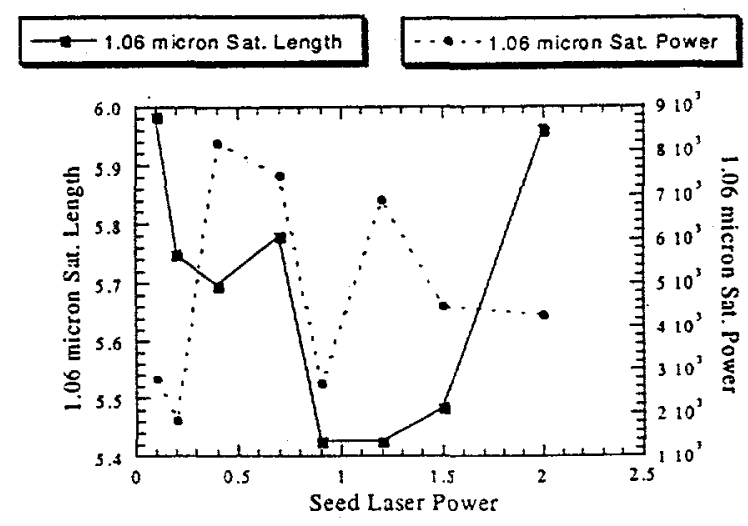

(e)

Figure 4: Saturation Length (m) and Saturated Power (W) versus input seed laser power (MW) for the (a) $5.3 \mu \mathrm{m}$, (b) $2.65 \mu \mathrm{m}$, (c) $1.77 \mu \mathrm{m}$, (d) $1.33 \mu \mathrm{m}$, and (e) 1.06 


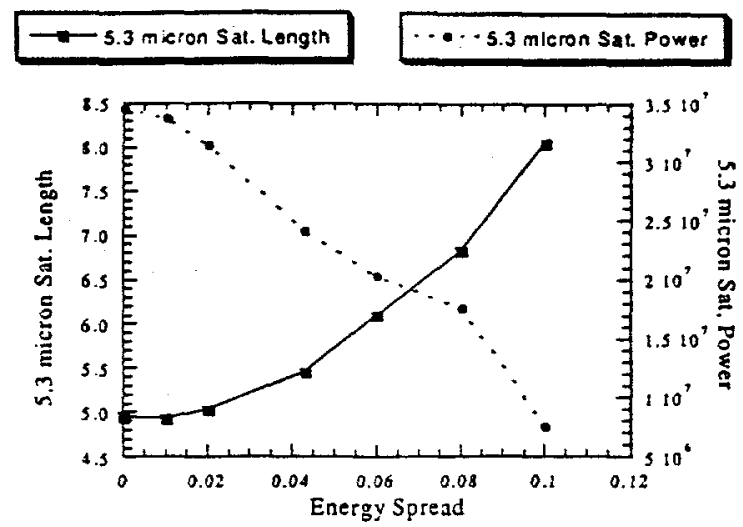

(a)

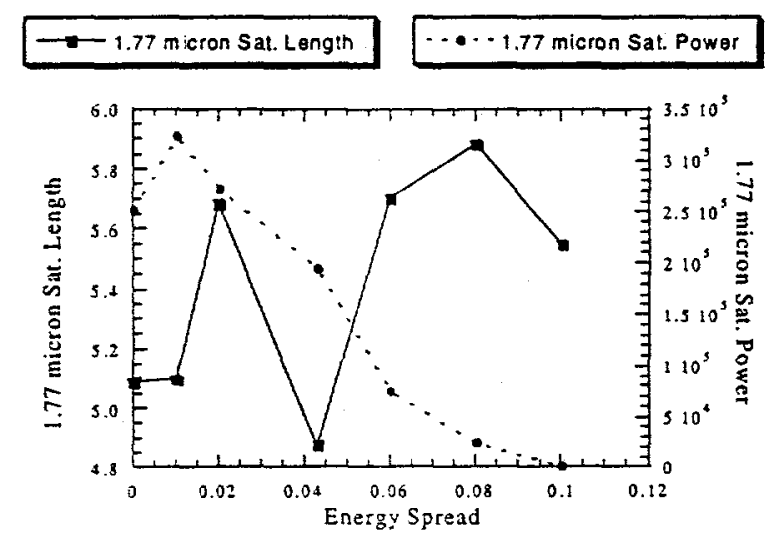

(c)

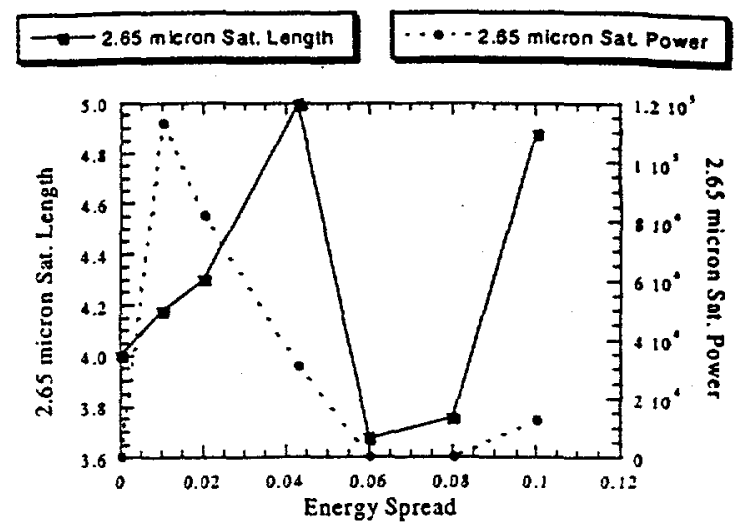

(b)

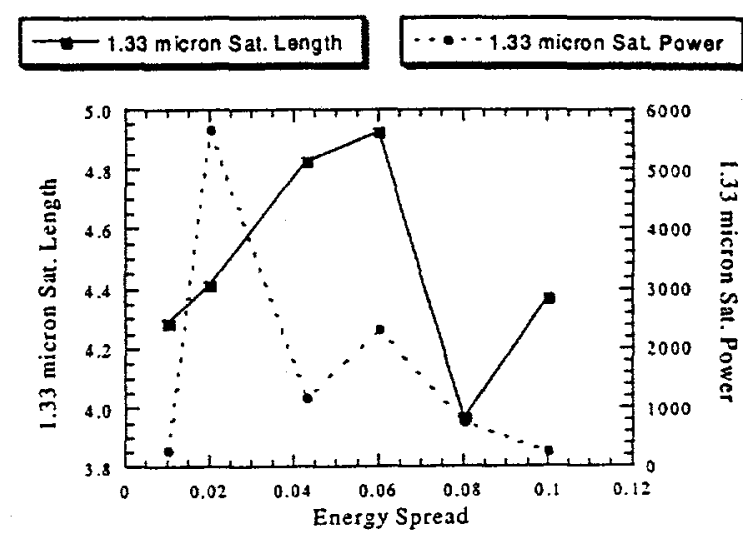

(d)

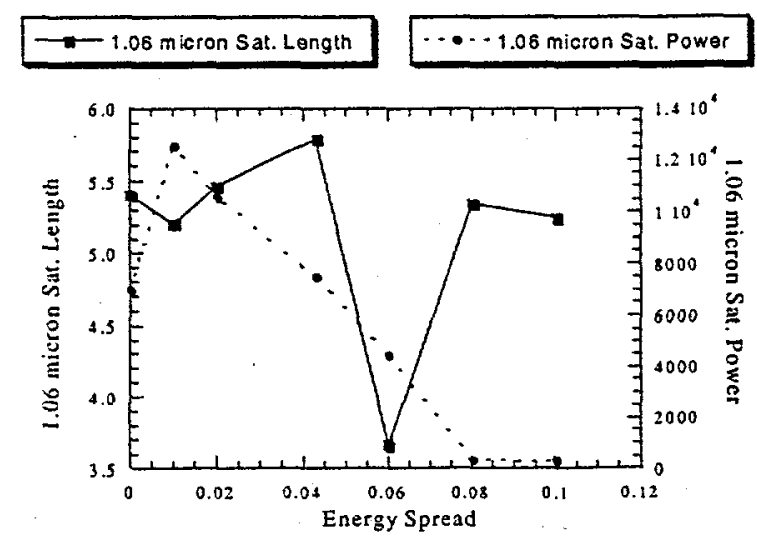

(e)

Figure 5: Saturation Length $(\mathrm{m})$ and Saturated Power (W) versus energy spread (\%) for the (a) $5.3 \mu \mathrm{m}$, (b) $2.65 \mu \mathrm{m}$, (c) $1.77 \mu \mathrm{m}$, (d) $1.33 \mu \mathrm{m}$, and (e) $1.06 \mu \mathrm{m}$ output radiation. 


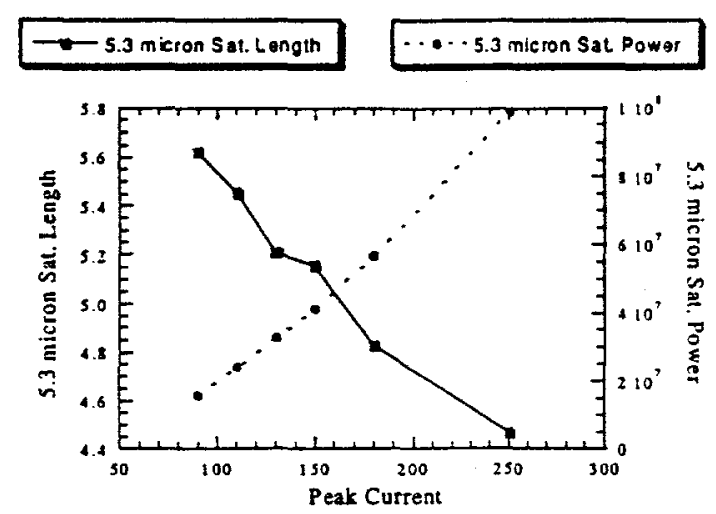

(a)

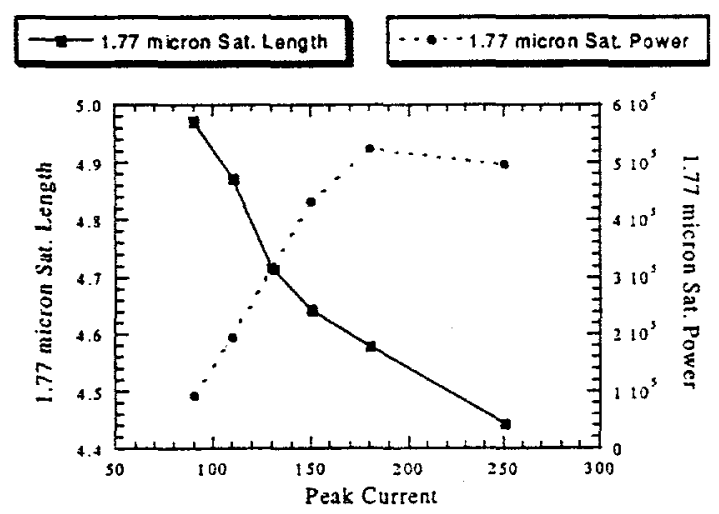

(c)

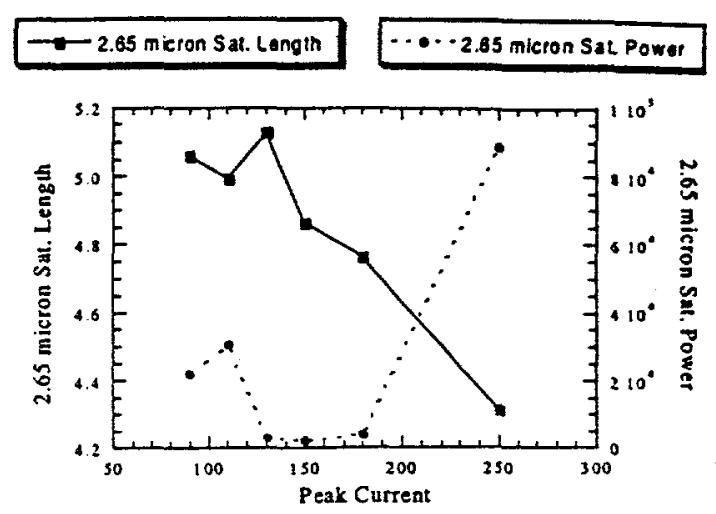

(b)

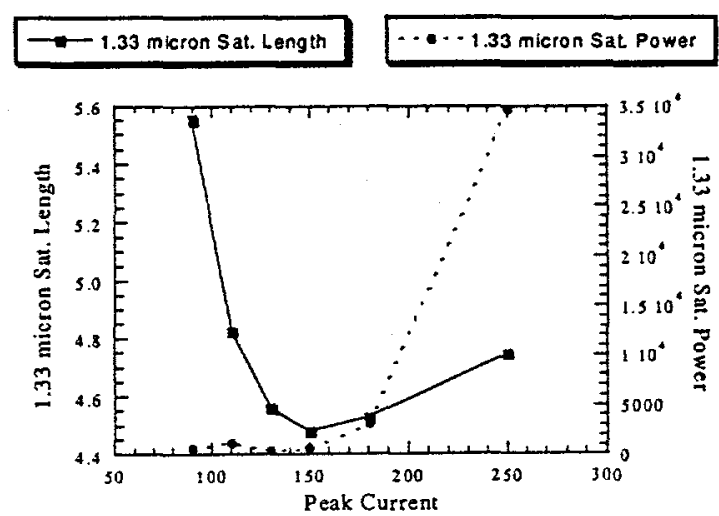

(d)

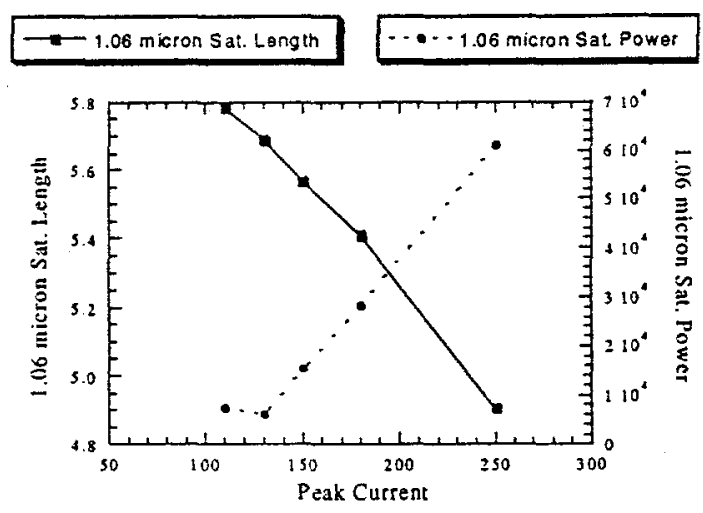

(e)

Figure 6: Saturation Length (m) and Saturated Power (W) versus peak current (A)

for the (a) $5.3 \mu \mathrm{m}$, (b) $2.65 \mu \mathrm{m}$, (c) $1.77 \mu \mathrm{m}$, (d) $1.33 \mu \mathrm{m}$, and (e) $1.06 \mu \mathrm{m}$ output radiation. 


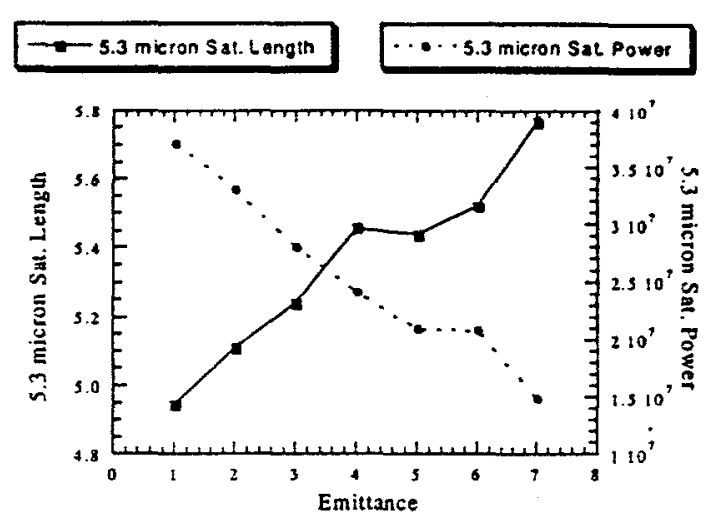

(a)

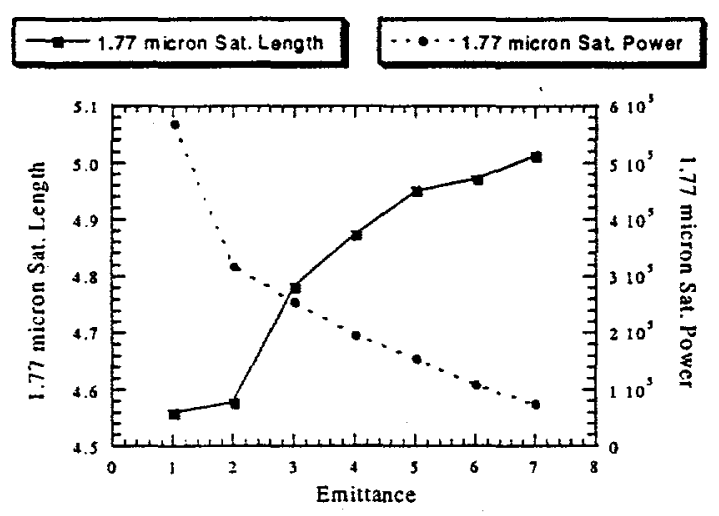

(c)

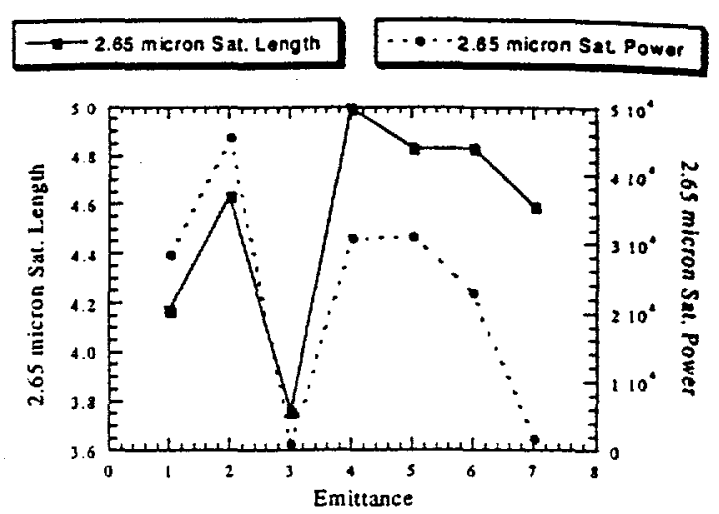

(b)

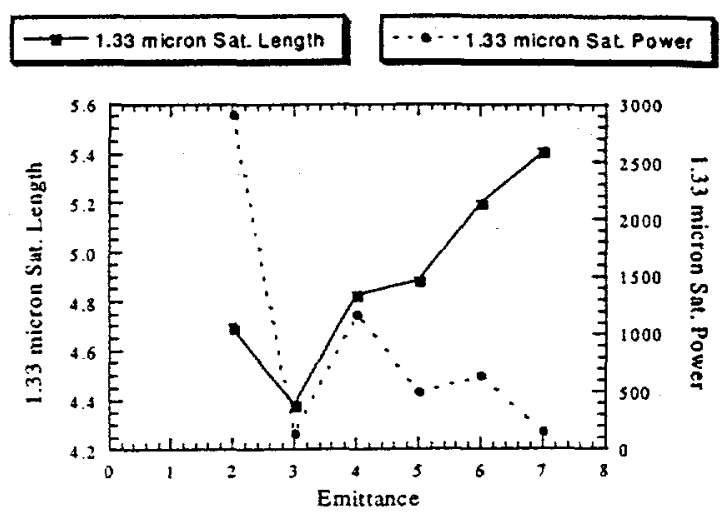

(d)

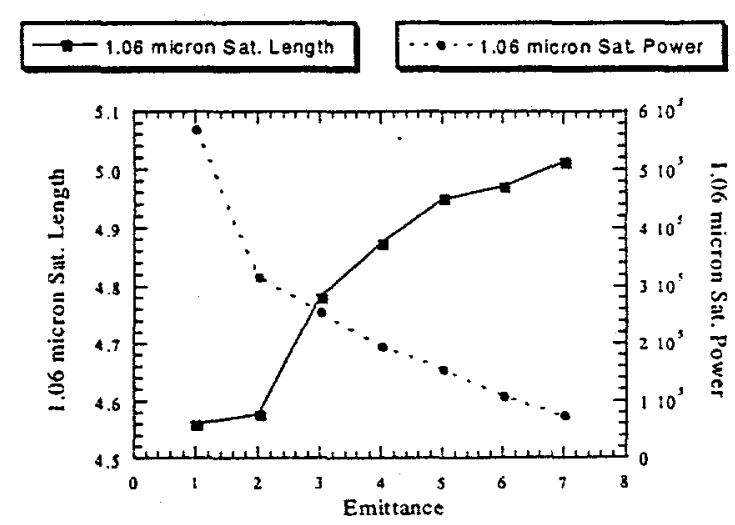

(e)

Figure 7: Saturation Length $(\mathrm{m})$ and Saturated Power $(\mathrm{W})$ versus emittance $(\pi \mathrm{mm}$ mrad) for the (a) $5.3 \mu \mathrm{m}$, (b) $2.65 \mu \mathrm{m}$, (c) $1.77 \mu \mathrm{m}$, (d) $1.33 \mu \mathrm{m}$, and (e) $1.06 \mu \mathrm{m}$ output radiation. 